Zsolt Szucs-Farkas

Michael A. Patak

Seyran Yuksel-Hatz

Thomas Ruder

Peter Vock

\section{Single-exposure dual-energy subtraction chest radiography: Detection of pulmonary nodules and masses in clinical practice}

Received: 19 April 2007

Revised: 28 June 2007

Accepted: 24 August 2007

Published online: 27 September 2007

(C) European Society of Radiology 2007
Z. Szucs-Farkas $(\bowtie) \cdot$ M. A. Patak ·

S. Yuksel-Hatz · T. Ruder · P. Vock

Department of Interventional and Diagnostic Radiology,

University Hospital of Berne,

Freiburgerstrasse 4,

Berne, CH-3010, Switzerland

e-mail: zsolt.szuecs@insel.ch

Fax: +41-31-6320570

\begin{abstract}
The purpose of this retrospective study was to evaluate the impact of energy subtraction (ES) chest radiography on the detection of pulmonary nodules and masses in daily routine. Seventy-seven patients and 25 healthy subjects were examined with a single exposure digital radiography system. Five blinded readers evaluated first the nonsubtracted PA and lateral chest radiographs alone and then together with the subtracted PA soft tissue images. The size, location and number of lung nodules or masses were registered with the confidence level. CT was used as standard of reference. For the 200 total lesions, a sensitivity of 33.5 $52.5 \%$ was found at non-subtracted and a sensitivity of $43.5-58.5 \%$ at energy-subtracted radiography, corresponding to a significant improvement
\end{abstract}

in four of five readers $(p<0.05)$. However, in three of five readers the rate of false positives was higher with ES. With ES, sensitivity, but not the area under the alternative freeresponse receiver operating characteristics (AFROC) curve, showed a good correlation with reader experience $(\mathrm{R}=0.90, \mathrm{p}=0.026)$. In four of five readers, the diagnostic confidence improved with ES $(p=0.0036)$. We conclude that single-exposure digital ES chest radiography improves detection of most pulmonary nodules and masses, but identification of nodules $<1 \mathrm{~cm}$ and false-positive findings remain a problem.

Keywords Dual-energy scanned projection radiography - Pulmonary coin lesion $\cdot$ Pulmonary neoplasms

\section{Introduction}

Despite the introduction of low-dose computed tomography (CT) for lung cancer screening, conventional chest radiography remains the primary and often the only diagnostic tool for excluding pulmonary nodules in clinical medicine. Yet while chest X-ray is cost effective and exposes the patient to markedly less ionizing radiation than $\mathrm{CT}$, it is clearly inferior to $\mathrm{CT}$ at detecting and characterizing both intra- and extrapulmonary pathologies, especially of smaller lesions. Technical innovations in the past 2 decades have improved the diagnostic quality of chest $\mathrm{X}$-ray. Besides computed radiography (CR) and flat panel detectors, great efforts have been made to reduce the disturbing effect of overlaying anatomic structures such as ribs, heart, pulmonary vessels and diaphragm on chest radiographs. In this respect, ribs are of special concern, overlaying as they do up to $75 \%$ of the lungs [1].

Dual-energy subtraction imaging is capable of producing bone and soft tissue images of the chest by subtracting two datasets recorded at low and high photon energies. At the present time, two main techniques are used to acquire image data at two separate energy levels. In the dualexposure technique, two X-ray images at different tube energies are shot at a brief interval of some hundreds of milliseconds, which produces a low noise level, but renders the image susceptible to motion artifacts. The single-shot technique uses a cassette with two CR plates and a thin copper filter between, which allows the passage of only high energy roentgen photons. With only a single exposure, 
a normal chest X-ray is generated on the first CR plate, while a bone image is generated on the second plate behind the copper filter. A soft tissue image is then achieved by subtracting the bone image from the normal radiograph. Image quality with this method, due in part to the different detector systems employed, is inferior to that produced by the dual-exposure technique. Single-exposure radiography, however, is not sensitive to motion artifacts and uses a lower radiation dose[1-5].

Up till now, the literature mostly has documented the better detection of calcified pulmonary nodules using the dual exposure technique or older single-shot exposure systems [6-14]. The latter, despite promising initial results, fell into disfavor because of their cumbersome handling and inconsistent image quality. Lately, the readout of both sides of the CR-imaging plates, formerly possible only with mammography and pediatric systems, became available also for chest radiography. This has improved detective quantum efficiency with single-exposure subtraction radiography [15-17]. Combined with rapid image processing, this development has the potential to overcome some of the drawbacks of the old single-exposure systems. To our knowledge, no data have yet been published on the performance of the newly developed single-shot dualenergy chest systems in clinical routine.

In the present study, we applied a single-shot digital chest radiography system with dual side plate reading technology to evaluate the utility of energy subtraction (ES) in the detection of pulmonary nodules $(\leq 3 \mathrm{~cm})$ and masses $(>3 \mathrm{~cm})$ by observers with varied clinical experience.

\section{Materials and methods}

\section{Patients}

The records of patients who had undergone single-shot digital subtraction radiography and CT of the chest in 2005 were selected from our database and analyzed. Inclusion criteria for the study were as follows: (1) single-shot digital subtraction radiography and chest CT performed within a period of 2 weeks with (2) no major surgery intervening between the two procedures and (3) a radiological report of the CT containing at least one of the following terms: pulmonary nodule, bronchial carcinoma, lung tumor or mass, round lesion, and pulmonary metastasis. If more than one chest radiograph was acquired in the same patient within the 2-week period, the radiograph taken closest to the CT was used in the study. Eighty patients matched the search criteria; three of them were excluded due to large pleural effusions obscuring more than two-thirds of the hemichest. In this manner, of the 9,715 single-shot digital subtraction radiographies and 2,211 chest CT examinations performed in 2005, those of 77 patients (52 male, 25 female; mean age 63.2 years, range 35-91 years) were selected for this retrospective study. The study was performed according to the regulations of the institutional review board.

\section{Control subjects}

Twenty-five patients (17 male, 8 female; mean age 61.8 years, range $28-89$ years) fulfilling selection criteria (1) and (2), but having neither a mass/nodule nor major pulmonary or lung disease at CT, were randomly selected for the control group.

\section{Digital radiography and chest $\mathrm{CT}$}

Digital chest radiography was performed on a Fuji XU-D1 (Fujifilm Medical, Tokyo, Japan) upright image reader system equipped with an 0.8 -mm-thin copper filter sandwiched between two $43 \times 43$-cm CR plates. The unit is routinely used for chest radiography in our department. Spatial resolution was set at standard pixel density ( 5 pixels $/ \mathrm{mm}$ ), equaling $2,140 \times 1,760$ pixels per image with a format of $43 \times 35 \mathrm{~cm}$ (effective reading size of $428 \times 352 \mathrm{~mm}$ ). The $\mathrm{X}$-ray tube potential was $125 \mathrm{kVp}$ for the PA and $141 \mathrm{kVp}$ for the lateral view; the focus-cassette distance was constantly set at $2 \mathrm{~m}$. Tube current was selected automatically by the unit at a reference dose of $3.5 \mu \mathrm{Gy}$.

CT examinations were done on a multi-detector scanner (Siemens Somatom Cardiac 64, Siemens Medical Solutions, Forchheim, Germany) at $100 \mathrm{kVp}$ tube energy with a tube rotation time of $0.5 \mathrm{~s}$, a collimation of $24 \times 1.2 \mathrm{~mm}$, pitch of 1.125 and continuous reconstruction at $2 \mathrm{~mm}$ and $5 \mathrm{~mm}$. We used the built-in real-time dose modulation software provided by the manufacturer (CareDose4D); the reference tube current time product was set at $100 \mathrm{mAs}$. For CT, $80 \mathrm{ml}$ contrast agent of $350 \mathrm{mg}$ iodine $/ \mathrm{ml}$ (Ioversol, Optiray 350, Tyco Healthcare/Mallinckrodt, St. Louis, MO) was administered intravenously at a flow rate of $3-4 \mathrm{ml} / \mathrm{s}$. All images were stored in a picture archiving and communication system.

Image analysis with digital chest radiography

All patient data except for age and gender were removed from the digital radiographs. Five blinded board-certified radiologists with a professional experience of 0.5 to 30 years read the anonymized images of the 102 subjects in a randomized order. Four of the readers are general radiologists; the fifth and most experienced is subspecialized in thoracic radiology. At the time of the study, readers had an experience of 2 months to 2 years with energy subtraction. The observers were asked to look for pulmonary nodules or round masses on the radiographs. Findings 
were registered on evaluation sheets especially designed for this study. The sheets provided two sections for recording of the (1) number, (2) size and (3) location of pulmonary lesions in a first reading without ES and a second reading with ES. Nodules measuring $<5 \mathrm{~mm}$ on the radiograph were not registered. Since six or more lesions do not have an impact on the therapeutic decision, a maximum of five nodules and/or masses per patient was analyzed. If more than five lesions measuring $\geq 5 \mathrm{~mm}$ were seen in the same patient, only the largest was analyzed, and the number of lesions was registered as " $>5$." Lung pathologies other than nodules or masses (e.g., consolidation, atelectasis, and interstitial lung disease) as well as pleural disease (e.g., effusion and pneumothorax) were not regarded as positive findings, but were noted by the readers on the evaluation sheet as factors lowering the diagnostic confidence. The observers first analyzed the non-subtracted digital PA radiograph of the chest with the lateral view simultaneously on two high-resolution liquid crystal display (LCD) monitors. After noting their opinion on the evaluation form, they were then allowed to access the digitally subtracted soft tissue and bone PA images in the same session, thus simulating the clinical situation of having both subtracted and non-subtracted images available. Again, the appropriate fields of the evaluation sheet were filled in. The level of confidence for each diagnosis without and with ES was graded using a five-level scoring system $(1=$ definite round lesion, $2=$ probable round lesion, $3=$ possible round lesion/equivocal, $4=$ probably no round lesion, $5=$ definitely no round lesion). Each reader also recorded their opinion on the helpfulness of the digital ES $(1=$ no contribution to diagnosis, $2=$ small contribution to diagnosis, $3=$ significant contribution to diagnosis, and $4=$ significant contribution with diagnosis of new round lesion).

Table 1 Summary of diagnoses in 77 study patients and size ranges of the 200 pulmonary lesions detected in chest CT

\begin{tabular}{lll}
\hline Diagnosis & Patients $(\mathrm{n}=77)$ & Lesions $(\mathrm{n}=200)$ \\
\hline Primary lung cancer & 34 & 56 \\
Pulmonary metastases & 27 & 97 \\
Lymphoma & 3 & 6 \\
Aspergillosis & 2 & 10 \\
Wegener's granulomatosis & 2 & 9 \\
Sarcoidosis & 1 & 5 \\
No histology & 8 & 17 \\
Total & 77 & 200 \\
Classification of & Size range & $\mathrm{n}$ \\
lesions by size & $5-9 \mathrm{~mm}$ & 93 \\
(n=200) & $10-30 \mathrm{~mm}$ & 70 \\
& $>30 \mathrm{~mm}$ & 37 \\
Total & & 200 \\
\hline
\end{tabular}

\section{Image analysis with $\mathrm{CT}$}

One of the authors (Z.S.) analyzed the corresponding 2-mm axial CT images of all patients and control subjects at both mediastinal and lung window settings. In some selected cases, coronal maximum intensity projection images were also necessary for a better depiction of the pulmonary findings. The number, location, and size for each lesion
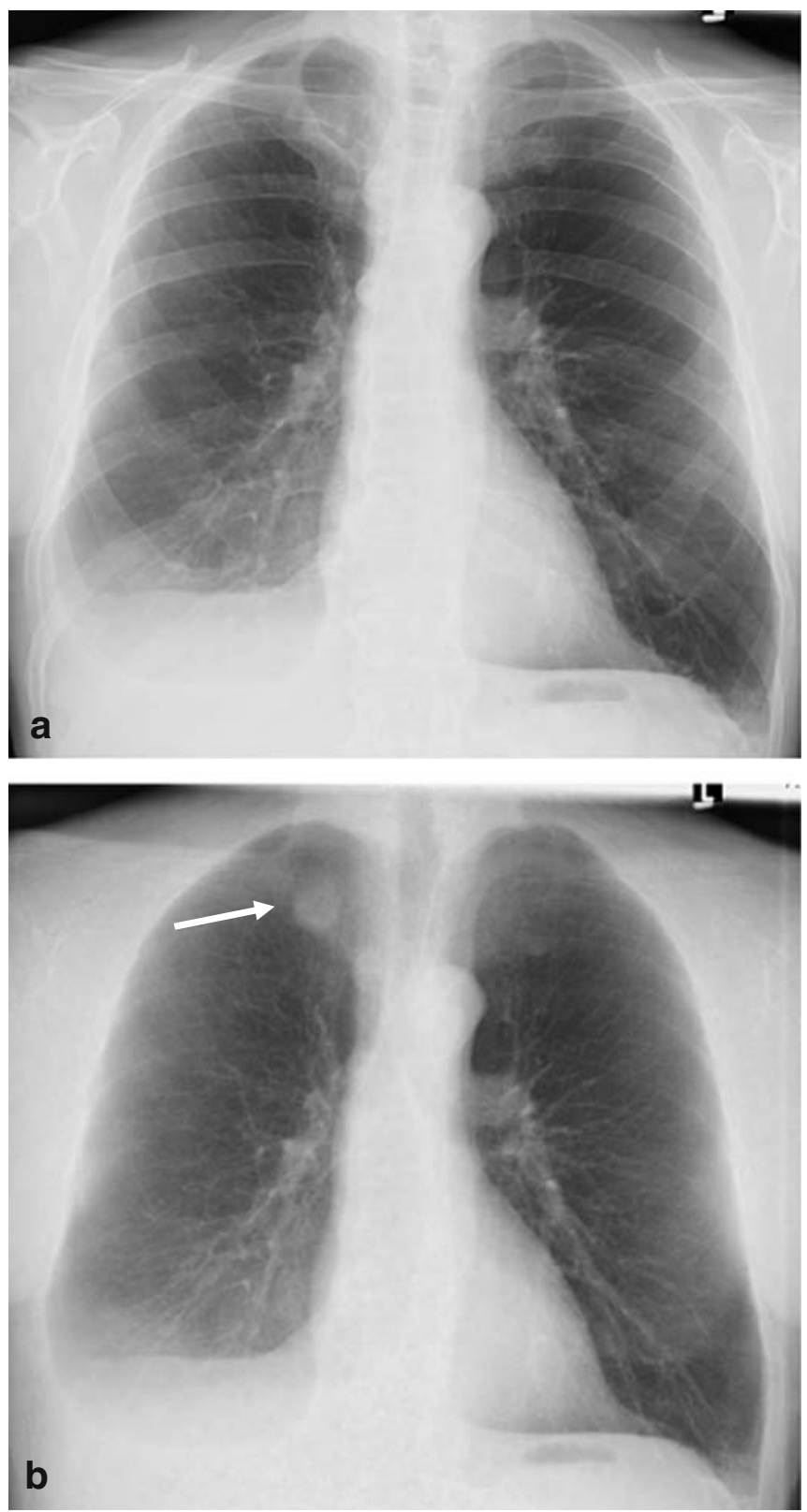

Fig. 1 Posteroanterior non-subtracted digital chest radiograph (a) and the corresponding soft tissue image (b) in a 73-year-old male with metastatic carcinoma of the oropharynx. The solitary peripheral nodule in the right upper lobe (white arrow) is partially superimposed by bony structures on the standard radiograph and better depicted in the soft tissue image 
measuring at least $5 \mathrm{~mm}$ along with the presence of calcification were noted. If more than five lesions were present, only the five largest were analyzed and the number of lesions registered as " $>5$." Significant pleural effusions, pneumothorax, postoperative changes, dystelectasis and consolidations were also documented.

\section{Data analysis and statistics}

The data on the evaluation sheets of the five readers were compared to the CT findings. True-positive lesions and false-positive images were counted at all confidence levels using the alternative free-response receiver-operating characteristic methodology (AFROC). This approach allows the analysis of multiple pathologies per image, takes into account nodule localization and does not require the Poisson assumption about the distribution of false-positive responses. The AFROC curve plots the fraction of detected nodules against the probability of a false-positive image. The reader performance is characterized by the area under the AFROC curve $\left(\mathrm{A}_{1}\right)$, which can be calculated by the ROCFIT program [18]. Although this program is primarily designated for analyzing conventional receiver-operating characteristic (ROC) data, it can also be used for the analysis of AFROC data tables [7, 19].

Sensitivity, specificity, accuracy and area under the AFROC curve with and without ES were compared with the Student's t-test. Each reader's performance was correlated with their professional experience using the Spearman's rank correlation. Confidence levels with and without ES in the same reader were compared using the Wilcoxon matched pairs test. Kappa-statistics were used to assess the interobserver agreement in a lesion-to-lesion manner. Agreement between the readers was graded as follows: $<0.20$ poor , $0.21-0.40$ fair, $0.41-0.60$ moderate, $0.61-0.80$ good, and $0.81-1.00$ very good.

\section{Results}

Two hundred pulmonary round lesions were found at CT (163 nodules, 37 masses; median size $10 \mathrm{~mm}$, range 5$116 \mathrm{~mm}$; lower quartile $6 \mathrm{~mm}$; upper quartile $22 \mathrm{~mm}$ ). Calcification was present in only four nodules. Sixty-one of the 77 patients had malignant pulmonary lesions confirmed by histology (Table 1) (Fig. 1).

Sensitivity, specificity, accuracy, and the area under the AFROC curve are summarized in Table 2. With ES, $\mathrm{A}_{1}$ improved in four readers, but the increase failed to reach statistical significance $(p=0.124-0.918)$. Four of the five readers achieved significantly higher true-positive rates with ES than without $(\mathrm{p}<0.05)$. ES, however, resulted in a significantly higher rate of false-positive findings and a decreased specificity in readers 1,2 , and $3(\mathrm{p}<0.05)$. Not surprisingly, for pulmonary lesions measuring $\geq 10 \mathrm{~mm}$, all readers found significantly higher sensitivity, specificity, accuracy and $\mathrm{A}_{1} \mathrm{~s}(\mathrm{p}<0.003$, Table 3). Except for the sensitivity in two readers, results for all lesions $\geq 10 \mathrm{~mm}$ were very similar to those for nodules measuring 10 to $30 \mathrm{~mm}$. The two least experienced readers did not recognize a mass in lung atelectasis or could not distinguish between masses and pneumonia in five patients, resulting in false-negative results (Fig. 2). All other masses were detected both without and with ES by all readers and no false-positive masses were found.

With ES, the correlation between reader experience and the number of true-positive nodules and sensitivity was very good (Spearman $\mathrm{R}=0.90, \mathrm{p}=0.026$ ). Without $\mathrm{ES}$, there was a strong correlation between reader experience

Table 2 Readers' performance for all pulmonary nodules and masses $(n=200)$

\begin{tabular}{|c|c|c|c|c|c|c|c|c|c|c|}
\hline \multicolumn{2}{|c|}{ Reader (experience) } & \multicolumn{9}{|c|}{ All pulmonary lesions $(n=200)$} \\
\hline & & TP & $\mathrm{FN}$ & FP & $\mathrm{TN}$ & $\begin{array}{l}\text { Accuracy } \\
(\%)\end{array}$ & $\begin{array}{l}\text { Sensitivity } \\
(\%)\end{array}$ & $\begin{array}{l}\text { Specificity } \\
(\%)\end{array}$ & $\mathrm{A}_{1}$ & $\mathrm{SD} \mathrm{A}_{1}$ \\
\hline $\begin{array}{l}\text { Reader } 1 \\
\text { (11 years) }\end{array}$ & w/o ES with ES & 105106 & 9594 & 2129 & 2019 & 51.950 .4 & 52.553 .0 & 48.839 .6 & 0.5590 .537 & 0.05750 .0472 \\
\hline $\begin{array}{l}\text { Reader } 2 \\
\quad(30 \text { years })\end{array}$ & w/o ES with ES & 103117 & 9783 & 2129 & 2019 & 50.855 .0 & 51.558 .5 & 48.839 .6 & 0.5950 .623 & 0.04030 .0339 \\
\hline $\begin{array}{l}\text { Reader } 3 \\
\text { (4 years) }\end{array}$ & w/o ES with ES & 8495 & 116105 & 4455 & 2219 & 40.041 .8 & 42.047 .5 & 33.325 .7 & 0.4460 .470 & 0.03820 .0368 \\
\hline $\begin{array}{l}\text { Reader } 4 \\
\text { (7 years) }\end{array}$ & w/o ES with ES & 8793 & 113107 & 1312 & 2324 & 46.649 .6 & 43.546 .5 & 63.966 .7 & 0.5060 .565 & 0.04940 .0444 \\
\hline $\begin{array}{l}\text { Reader } 5 \\
\text { (1/2 years })\end{array}$ & w/o ES with ES & 6687 & 134113 & 2119 & 2121 & 36.045 .0 & 33.343 .5 & 50.052 .5 & 0.4940 .554 & 0.06010 .0627 \\
\hline
\end{tabular}

$\mathrm{ES}=$ energy subtraction, $\mathrm{TP}=$ true positive, $\mathrm{FN}=$ false negative, $\mathrm{FP}=$ false positive, $\mathrm{TN}=$ true negative. $\mathrm{A}_{1}=$ area under the alternative freeresponse receiver-operating characteristics (AFROC) curve; $\mathrm{SD} \mathrm{A}_{1}=$ standard deviation of the area under the AFROC curve. 
Table 3 Accuracy, sensitivity, specificity and $\mathrm{A}_{1}$ for lung nodules $\geq 10 \mathrm{~mm}$ and masses, and for pulmonary nodules measuring $10-30 \mathrm{~mm}$

\begin{tabular}{|c|c|c|c|c|c|c|c|c|c|c|c|}
\hline \multicolumn{2}{|c|}{ Reader (experience) } & \multicolumn{5}{|c|}{ Pulmonary nodules $\geq 10 \mathrm{~mm}$ and masses $(\mathrm{n}=107)$} & \multicolumn{5}{|c|}{ Pulmonary nodules $10-30 \mathrm{~mm}(\mathrm{n}=70)$} \\
\hline & & $\begin{array}{l}\text { Accuracy } \\
(\%)\end{array}$ & $\begin{array}{l}\text { Sensitivity } \\
(\%)\end{array}$ & $\begin{array}{l}\text { Specificity } \\
(\%)\end{array}$ & $\mathrm{A}_{1}$ & $\mathrm{SD} \mathrm{A}$ & $\begin{array}{l}\text { Accuracy } \\
(\%)\end{array}$ & $\begin{array}{l}\text { Sensitivity } \\
(\%)\end{array}$ & $\begin{array}{l}\text { Specificity } \\
(\%)\end{array}$ & $\mathrm{A}_{1}$ & $\mathrm{SD} \mathrm{A}_{1}$ \\
\hline \multirow{2}{*}{$\begin{array}{l}\text { Reader } 1 \\
\text { (11 years) }\end{array}$} & W/o ES & 70.7 & 73.8 & 60.6 & 0.781 & 0.0518 & 65.1 & 67.1 & 60.6 & 0.750 & 0.0548 \\
\hline & With ES & 68.1 & 74.5 & 50.0 & 0.778 & 0.0435 & 60.6 & 67.1 & 50.0 & 0.741 & 0.0489 \\
\hline \multirow{2}{*}{$\begin{array}{l}\text { Reader } 2 \\
\text { (30 years) }\end{array}$} & W/o ES & 74.6 & 78.4 & 62.5 & 0.810 & 0.0371 & 75.0 & 80.9 & 62.5 & 0.798 & 0.0460 \\
\hline & With ES & 73.4 & 79.6 & 57.6 & 0.810 & 0.0354 & 75.2 & 82.9 & 57.6 & 0.802 & 0.0421 \\
\hline \multirow{2}{*}{$\begin{array}{l}\text { Reader } 3 \\
\text { (4 years) }\end{array}$} & W/o ES & 59.1 & 62.3 & 51.2 & 0.699 & 0.0430 & 57.4 & 61.1 & 51.2 & 0.696 & 0.0492 \\
\hline & With ES & 58.1 & 67.0 & 38.8 & 0.721 & 0.0408 & 54.5 & 67.1 & 38.8 & 0.737 & 0.0461 \\
\hline \multirow{2}{*}{$\begin{array}{l}\text { Reader } 4 \\
\text { (7 years) }\end{array}$} & W/o ES & 71.7 & 71.0 & 74.2 & 0.717 & 0.0469 & 70.2 & 68.5 & 74.2 & 0.696 & 0.0535 \\
\hline & With ES & 73.9 & 72.9 & 77.4 & 0.808 & 0.0375 & 73.1 & 71.2 & 77.4 & 0.803 & 0.0441 \\
\hline \multirow{2}{*}{$\begin{array}{l}\text { Reader } 5 \\
(1 / 2 \text { years })\end{array}$} & W/o ES & 52.4 & 49.6 & 61.8 & 0.685 & 0.0599 & 49.1 & 43.8 & 61.8 & 0.671 & 0.0639 \\
\hline & With ES & 57.0 & 55.6 & 61.8 & 0.726 & 0.0584 & 52.8 & 48.6 & 61.8 & 0.708 & 0.0689 \\
\hline
\end{tabular}

Please note that nodules analyzed on the right side of the table are a subgroup of lesions on the left side. Lung masses $>3 \mathrm{~cm}$ are responsible for the differences between the two sides, reaching statistical significance for sensitivity in readers 1 and 5 ( $p<0.05$ ). There is no difference in specificity, since no false-positive masses were found.

$\mathrm{A}_{1}=$ area under the alternative free-response receiver-operating characteristics (AFROC) curve; SD $\mathrm{A}_{1}=$ standard deviation of the area under the AFROC curve.

Fig. 2 Fifty-two-year-old female patient with primary bronchus carcinoma in the middle lobe. The standard posteroanterior chest radiograph (a) shows a diffuse decreased transparence of the right lower lung field. No additional information on the subtracted radiograph $(\mathbf{b})$. The lateral view (c) depicts the atelectasis of the middle lobe with displaced fissures and a mass in the apical-central region of the lobe, which was not recognized by two observers. The transverse CT scan (d) clearly shows a cavitating lung tumor with thick irregular walls
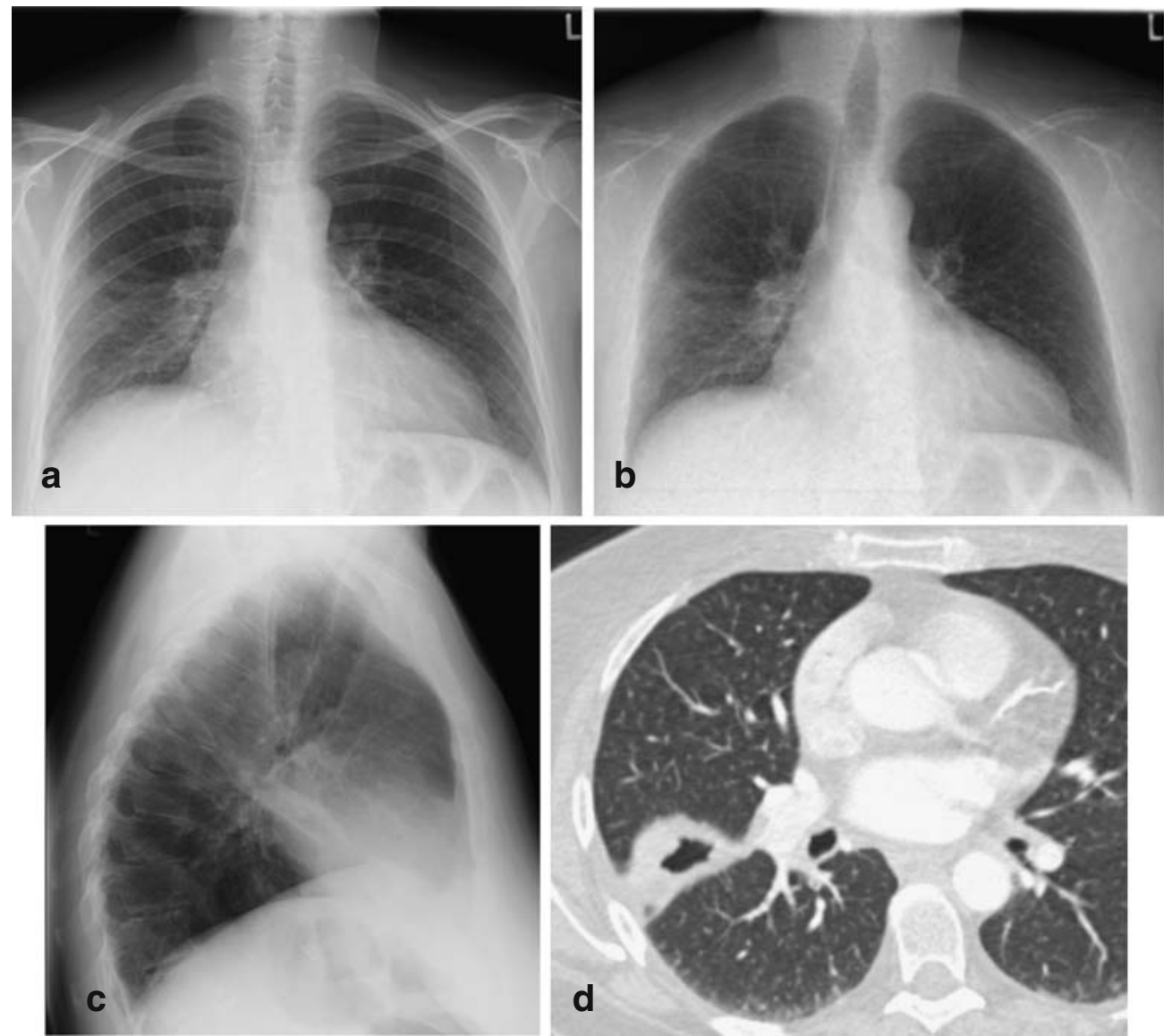
and the $\mathrm{A}_{1}$ for all lesions (Spearman $\mathrm{R}=0.90, \mathrm{p}<0.05$ ). With ES, the $A_{1}$ for all lesions, or the $A_{1}$ for lesions $\geq$ $10 \mathrm{~mm}$ with or without $\mathrm{ES}$, did not correlate with reader experience $(p>0.11)$. There was also no correlation between reader experience and specificity for all types of lesion ( $\mathrm{p}>0.71)$.

Observers found ES helpful in $54 \%$ to $82 \%$ of cases, reporting that it contributed significantly to diagnosis or showed additional findings in $40 \%$ to $55 \%$ of patients. The descriptive statistics for lung nodules detected only with ES are given in Table 4. Of these lesions, $20 \%$ to $50 \%$ were false-positive findings having no correlate in CT. The rate of these false positives was independent of reader experience $(p>0.74)$.

All radiologists except for reader 1 reached a significantly higher diagnostic confidence with the additional information of ES than without it $(\mathrm{p}<0.004$; Table 5). The confidence level did not correlate with reader experience $(\mathrm{p}>0.43)$. Interobserver agreement was moderate to good (kappa-values without ES, 0.425-0.681, with ES, 0.412$0.655)$.

\section{Discussion}

Conventional chest radiography is hampered by both quantum mottle and anatomical (structured) noise, which impede detection of pulmonary nodules. Anatomical noise can mask lesions smaller than $8 \mathrm{~mm}$ or closely resemble lung pathology. It has been shown to be a more important limiting factor than random noise in the detection of small pulmonary nodules $[20,21]$. The noise caused by the ribs projecting over the lungs can be efficiently reduced or eliminated by dual-energy imaging. Newly developed single-shot dual-energy chest radiography systems with the readout of both sides of the imaging plate have shown promise to improve the signal-to-noise ratio. Moreover, the image processing time of $30 \mathrm{~s}$ is clearly shorter than that reported in older studies [13].

Our aim in the present study was to test the use of singleshot subtraction radiography in the detection of pulmonary
Table 5 Level of confidence with standard digital radiography versus that with energy subtraction on a three-grade scale $(1=$ indeterminate diagnosis; 2 =probable diagnosis; $3=$ definite diagnosis)

\begin{tabular}{llll}
\hline & \multicolumn{2}{l}{ Confidence (mean) } & $\mathrm{p}$ \\
\cline { 2 - 3 } & Without ES & With ES & \\
\hline Reader 1 & 2.473 & 2.467 & 0.87 \\
Reader 2 & 2.521 & 2.635 & 0.0012 \\
Reader 3 & 2.012 & 2.102 & 0.0016 \\
Reader 4 & 2.275 & 2.401 & $<0.0001$ \\
Reader 5 & 2.510 & 2.599 & 0.0036 \\
\hline
\end{tabular}

$P$ values were calculated with the Wilcoxon test. Except for reader 1 , all readers reached a higher confidence level with energy subtraction

nodules $(\leq 3 \mathrm{~cm})$ and masses $(>3 \mathrm{~cm})$ in everyday practice. We therefore did not restrict the study to patients with calcified nodules only or to those having clear coin lesions without other pulmonary or pleural disease, but sought to reflect real clinical circumstances by including patients with small effusions, pneumothorax, consolidation or atelectasis. Only three patients with large pleural effusions obscuring more than two-thirds of a hemithorax were excluded. The study design explains why we did not reach an accuracy of $100 \%$ for pulmonary masses $(>3 \mathrm{~cm})$. Irregular lung masses can be mistaken for pneumonia or may be difficult to identify in atelectatic lobes, resulting in false negatives as was the case in five patients for our two least experienced observers. Furthermore, ES cannot eliminate the noise from overprojecting soft tissue structures such as pulmonary vessels, diaphragm, and heart, or due to changes in the lung parenchyma. These can obscure even large nodules, a diagnostic problem that can only be solved by CT or follow-up chest X-ray.

The accuracy and AFROC statistics for the total of 200 pulmonary lesions were rather poor based on $\mathrm{A}_{1} \mathrm{~s}$ of about 0.5 . The number of small lung nodules measuring $<10 \mathrm{~mm}$, amounting to $47 \%$ of all lesions, was undoubtedly responsible for these results. All readers performed significantly better for nodules $\geq 1 \mathrm{~cm}$. These findings underline the known limitations of conventional chest radiography, namely its

Table 4 Analysis of pulmonary nodules detected with dual-energy subtraction, but missed on conventional chest radiograph

\begin{tabular}{|c|c|c|c|c|c|c|c|c|}
\hline & \multirow[t]{2}{*}{ Number of patients } & \multirow[t]{2}{*}{ Number of new lesions } & \multicolumn{3}{|c|}{ True positive } & \multicolumn{3}{|c|}{ False positive } \\
\hline & & & $10-30 \mathrm{~mm}$ & $5-9 \mathrm{~mm}$ & Total & $10-30 \mathrm{~mm}$ & $5-9 \mathrm{~mm}$ & Total \\
\hline Reader 1 & 16 & 17 & 6 & 3 & 9 & 2 & 6 & 8 \\
\hline Reader 2 & 21 & 30 & 7 & 14 & 21 & 2 & 7 & 9 \\
\hline Reader 3 & 21 & 24 & 6 & 6 & 12 & 2 & 10 & 12 \\
\hline Reader 4 & 10 & 10 & 5 & 3 & 8 & 2 & 0 & 2 \\
\hline Reader 5 & 17 & 23 & 14 & 3 & 17 & 3 & 3 & 6 \\
\hline
\end{tabular}

For reader 3 , more the half of these nodules were false positives (i.e., no correlate on $\mathrm{CT})$, the rate being even higher for small $(<10 \mathrm{~mm})$ lesions. No additional lung masses $(>3 \mathrm{~cm})$ were detected with dual-energy subtraction. 
inability to substitute for $\mathrm{CT}$, especially for smaller lesions. It is also noteworthy that calcification, which facilitates detection on chest radiography, especially in subtle lung nodules, was not present in $98 \%$ of the nodules and masses in this study, and thus may have contributed to the rather weak result. Depending on geographical factors, different populations show different frequencies of calcified granulomas (often tuberculomas and histoplasmomas). The population studied here obviously has a low rate of granulomas.

Ricke at al. analyzed 59 non-calcified lesions with double-exposure subtraction radiography and reported sensitivities of $33 \%$ without and of $42 \%$ with ES [11]. These results are hardly comparable with ours, since their study included no pulmonary masses and half of the lesions were $<5 \mathrm{~mm}$. They also reported that only experienced readers profited significantly from ES images, less experienced readers showing only a trend toward improvement. We found that for all lesions $A_{1}$ without ES correlated well with reader experience, but for lesions $>1 \mathrm{~cm}$ this was no longer true. For all lesions, sensitivity with ES correlated with reader experience. We interpret these results as follows: Experienced readers are more familiar with normal chest radiographs and are less distracted by the overprojecting bony structures. This results in more truepositive and fewer false-positive findings, leading to higher $A_{1}$. The advantage of long experience is more pronounced in the detection of small nodules $(5-9 \mathrm{~mm})$. Lesions measuring at least $1 \mathrm{~cm}$ are more easily detected by inexperienced readers, so the difference in $\mathrm{A}_{1} \mathrm{~s}$ between readers decreases below statistical significance. Adding subtracted images significantly increased sensitivity in four out of five readers. This means that even radiologists with less experience profited from adding soft tissue images, although experienced readers still attain greater sensitivity with ES. Some of the nodules detected additionally on the soft tissue images turned out to be false positive, which decreased specificity in four readers. The result of these effects was that the overall performance as characterized by the area under the AFROC curve neither increased significantly nor did it depend on reader experience.
It is remarkable that specificity with ES did not depend on reader experience, false-positive findings, especially in the 5-9 mm range, being a diagnostic problem for all five radiologists. However, four of the five readers, independent of their experience, found ES helpful for diagnosis and attained a higher diagnostic confidence with it.

It is a potential limitation of this study that nodules measuring $<5 \mathrm{~mm}$ were not evaluated. The rationale for doing so was based on the experience of Henschke et al. [22], who found no growth in pulmonary lesions smaller than $5 \mathrm{~mm}$ in patients undergoing the first annual repeat lung cancer screening with $\mathrm{CT}$. In a consensus statement the malignancy rate in lung nodules $<5 \mathrm{~mm}$ was estimated to be not higher than $1 \%$ [23]. This indicates that lung nodules of this size are clinically most probably not relevant for the exclusion of pulmonary malignancy.

The aim of our work was to analyze if energy subtraction helps to detect pulmonary lesions and/or it increases diagnostic confidence in clinical routine. In our opinion, especially the latter issue can be better evaluated if the radiographs without and with ES of the same patient are showed successively to the reader. We are aware that this design may introduce a potential bias to the results. We also considered to read subtracted and non-subtracted images of various patients in a randomized order, but this idea was rejected as it does not reflect the real clinical situation, when radiologists make their decisions possessing both type of radiographs. It must be also stressed that we focused on nodule and mass detection only; lesion characterization in respect to malignant or benign nature of the findings was not our aim.

We showed that both experienced radiologists and their less experienced colleagues can profit from ES for the detection of pulmonary lesions on digital chest radiographs. Regardless of experience, however, nodules $<10 \mathrm{~mm}$ remain a problem. While the use of ES increased sensitivity, it also produced lower specificity. It remains for a future randomized study to assess the impact of the latest technical improvements in single-shot devices on signalto-noise ratio and detection of lesions as compared with dual-exposure flat-panel detector systems.

\section{References}

1. McAdams HP, Samei E, Dobbins J, 3rd, Tourassi GD, Ravin CE (2006) Recent advances in chest radiography. Radiology 241:663-683

2. Stewart BK, Huang HK (1990) Singleexposure dual-energy computed radiography. Medical Physics 17:866-875
3. Samei E, Flynn MJ (2002) An experimental comparison of detector performance for computed radiography systems. Medical physics 29:447-459

4. Fischbach F, Freund T, Pech M, Werk M, Bassir C, Stoever B, Felix R, Ricke J (2003) Comparison of indirect CsI/a: $\mathrm{Si}$ and direct a:Se digital radiography. An assessment of contrast and detail visualization. Acta Radiol 44:616-621
5. Gruber M, Uffmann M, Weber M, Prokop M, Balassy C, Schaefer-Prokop C (2006) Direct detector radiography versus dual reading computed radiography: feasibility of dose reduction in chest radiography. European Radiology 16:1544-1550 
6. Fraser RG, Hickey NM, Niklason LT, Sabbagh EA, Luna RF, Alexander CB, Robinson CA, Katzenstein AL, Barnes GT (1986) Calcification in pulmonary nodules: detection with dual-energy digital radiography. Radiology 160:595-601

7. Ho JT, Kruger RA (1989) Comparison of dual-energy and conventional chest radiography for nodule detection. Investigative Radiology 24:861-868

8. Oestmann JW, Greene R, Rhea JT, Rosenthal H, Koenker RM, Tillotson CL, Pearsen KD, Hill JW, Velaj RH (1989) "Single-exposure" dual energy digital radiography in the detection of pulmonary nodules and calcifications. Investigative Radiology 24:517-521

9. Samei E, Flynn MJ, Eyler WR (1997) Simulation of subtle lung nodules in projection chest radiography. Radiology 202:117-124

10. Kido S, Kuriyama K, Kuroda C, Nakamura H, Ito W, Shimura K, Kato H (2002) Detection of simulated pulmonary nodules by single-exposure dual-energy computed radiography of the chest: effect of a computer-aided diagnosis system (Part 2). European Journal of Radiology 44:205-209

11. Ricke J, Fischbach F, Freund T, Teichgraber U, Hanninen EL, Rottgen R, Engert U, Eichstadt H, Felix R (2003) Clinical results of CsIdetector-based dual-exposure dual energy in chest radiography. Eur Radiol 13:2577-2582
12. Uemura M, Miyagawa M, Yasuhara $\mathrm{Y}$, Murakami T, Ikura H, Sakamoto K, Tagashira H, Arakawa K, Mochizuki T (2005) Clinical evaluation of pulmonary nodules with dual-exposure dualenergy subtraction chest radiography. Radiation Medicine 23:391-397

13. Kido S, Ikezoe J, Naito H, Arisawa J, Tamura S, Kozuka T, Ito W, Shimura K, Kato H (1995) Clinical evaluation of pulmonary nodules with singleexposure dual-energy subtraction chest radiography with an iterative noisereduction algorithm. Radiology 194:407-412

14. Fischbach F, Freund T, Rottgen R, Engert U, Felix R, Ricke J (2003) Dualenergy chest radiography with a flatpanel digital detector: revealing calcified chest abnormalities. AJR 181:1519-1524

15. Fetterly KA, Schueler BA (2006) Performance evaluation of a computed radiography imaging device using a typical "front side" and novel "dual side" readout storage phosphors. Medical Physics 33:290-296

16. Monnin P, Holzer Z, Wolf R, Neitzel U, Vock P, Gudinchet F, Verdun FR (2006) An image quality comparison of standard and dual-side read CR systems for pediatric radiology. Medical Physics 33:411-420

17. Monnin P, Holzer Z, Wolf R, Neitzel U, Vock P, Gudinchet F, Verdun FR (2006) Influence of cassette type on the DQE of CR systems. Medical Physics 33:3637-3639

18. Eng J ROC analysis: web-based calculator for ROC curves http://www.jrocfit. org. Last updated:2006 May 17
19. Chakraborty DP, Winter LH (1990) Free-response methodology: alternate analysis and a new observerperformance experiment. Radiology 174:873-881

20. Samei E, Flynn MJ, Eyler WR (1999) Detection of subtle lung nodules: relative influence of quantum and anatomic noise on chest radiographs. Radiology 213:727-734

21. Samei E, Flynn MJ, Peterson E, Eyler WR (2003) Subtle lung nodules: influence of local anatomic variations on detection. Radiology 228:76-84

22. Henschke CI, Yankelevitz DF, Naidich DP, McCauley DI, McGuinness G, Libby DM, Smith JP, Pasmantier MW, Miettinen OS (2004) CT screening for lung cancer: suspiciousness of nodules according to size on baseline scans. Radiology 231:164-168

23. Aberle RD, Gamsu G, Henschke CI, Naidich DP, Swensen SJ (2001) Screening for Lung Cancer with Helical Computed Tomography: A Consensus Statement of the Society of Thoracic Radiology. J Thorac Imaging 16:65-68 